\title{
Initial factors predicting survival in patients with a spinal cord injury
}

\author{
P DAVERAT, M GAGNON, * J F DARTIGUES, * J M MAZAUX, M BARAT \\ From the Service de Rééducation Fonctionnelle Neurologique, Tastet Girard, Hôpital Pellegrin, Bordeaux and \\ Laboratoire d'Epidémiologie, * Biostatistiques, Informatique Médicale, Université de Bordeaux, Bordeaux, France
}

SUMMARY A study is presented of a prospective analysis of survival rates in 157 patients with spinal cord injury consecutively admitted to the Pellegrin Hospital (University Hospital, Bordeaux, France). There was a $20 \%$ death rate, occurring in the first three months after injury. Three independent predictors of survival in patients with spinal cord injuries (age, initial conscious level and respiratory assistance) were found by analysis of the course of the disorder.

The outcome of patients with a spinal cord injury (SCI) has improved with new management strategies including an early transfer to specialised units that provide intensive care facilities and services designed specifically for SCI patients. Nevertheless reported mortality rates in SCI patients remains variable; with figures ranging from $80 \%$ in $1946^{1}$ to $2.4 \%$ in 1982, , $^{2-5}$ The progress of medical care in the past 40 years is not sufficient to explain this difference. In Aquitaine (South-West region of France) an annual incidence of $25 /$ million was observed in 1983.6 The present study concerned $157 \mathrm{SCI}$ patients admitted to the emergency room of Pellegrin Hospital (University Hospital, Bordeaux). The major objective was to estimate mortality rates in SCI patients and to determine initial predictors of survival.

\section{Patients and methods}

Data were collected from January 1982 to July 1985 , on a consecutive sample of SCI patients initially admitted to the emergency ward of Pellegrin Hospital (Bordeaux, France). Within 6 hours after admission, our rehabilitation team systematically collected data on the initial state of SCI patients. Each subject was followed up regularly by one member of the team for a minimum period of 1 year.

Survival was studied as a function of time in a longitudinal prospective analysis. ${ }^{78}$ Several potential predictors were

Address for reprint requests: Dr P Daverat, Service de Réducation Fonctionnelle Neurologique, Tastet Girard, Hôpital Pellegrin, 33076 Bordeaux-Cedex, France.

Received 19 April 1988 and in revised form 23 September 1988. Accepted 6 October 1988 selected for the initial examination. These included age, level of lesion, Yale Scale Score (YSS), ${ }^{9}$ initial conscious level, multiple injuries, respiratory assistance and vegetative disorders. YSS allows grading of the sub-lesional neurological findings. It is a quantitative measurement which does not have the ambiguous characters of the ordinal scales generally used. ${ }^{10} 11$ The score is determined by motor and a sensory testing, each on a scale of 5 points. Total scores vary from 0 to 10; 0 indicates complete absence of motor and sensory function below the level of injury, while 10 corresponds to intact medullary function. This score is helpful since it is simple and reliable and can easily be administered in the emergency ward. Respiratory assistance was defined as compulsory assisted ventilation for more than 48 hours, this time being independent of any surgical intervention. Among the vegetative disorders, bradycardia (under 50 beats per minute) and hypotension (under $10 \mathrm{~mm} \mathrm{Hg}$ ) were recorded.

Univariate analysis (Kaplan-Meier method $^{12}$ ) was used in order to estimate the probability of survival as a function of time. Multivariate analysis (Cox model ${ }^{1314}$ ) was also used to determine independent predictors of survival in SCI patients.

\section{Results}

The total sample consisted of 157 patients, $82 \%$ were males, with a male/female ratio of 4 to 1 . During the first month of follow up, six subjects were lost while another five were lost in the following 6 months. The subjects ranged in ages from 5 to 86 years (mean age $=$ 38 years), $42 \%$ of the subjects being over 40 years. A peak was found in the range of 20 to 40 years. Within this population $52 \%$ were tetraplegic patients, $40 \%$ were injured at the C4-C5-C6 level. Among the paraplegic patients ( $48 \%$ of the population) the lesions were mainly found at the T3-T4 (11\%) and T11-T12 $(13 \%)$ levels. 
Table 1 Sample distribution as a function of initial factors (in \%)

\begin{tabular}{llll}
\hline Predictors & $\begin{array}{l}\text { Tetraplegic } \\
\text { patients }\end{array}$ & $\begin{array}{l}\text { Paraplegic } \\
\text { patients }\end{array}$ & Global \\
\hline $\begin{array}{l}\text { Initial consciousness: } \\
\quad \text { Normal }\end{array}$ & 59 & 61 & 60 \\
$\quad$ Obnubilation & 29 & 26 & 27 \\
$\quad$ Coma & 12 & 13 & 13 \\
$\begin{array}{l}\text { Multiple injuries: } \\
\quad \text { Thorax }\end{array}$ & 10 & 41 & \\
$\quad \begin{array}{l}\text { Abdomen } \\
\text { Limbs }\end{array}$ & 76 & 7 & 25 \\
$\quad \begin{array}{l}\text { Respiratory assistance: } \\
\text { Vegetative troubles: }\end{array}$ & 52 & 19 & 77 \\
$\quad$ Bradycardia & 56 & 25 & 39 \\
$\quad$ Hypotension & 28 & 19 & $37 \cdot 5$ \\
\hline
\end{tabular}

Predictors of survival (that is, initial conscious level, multiple injuries, respiratory assistance and vegetative troubles) are presented in table 1. Figures 1 and 2 show the survival curve for the total sample, tetraplegic patients and paraplegic patients. The global mortality rate was $20 \%$ at 3 months; $13 \%$ of the sample died in the first month following injury. Deaths did not occur after 3 months following SCI; life expectancy of these patients reached rates obtained for the general population. For tetraplegic patients, death rates consisted of $29 \%$ at 3 months (15\% died in the first month). Eleven per cent of all paraplegic patients died in the first month after injury.

With multivariate analysis, independent predictors of survival are age $(p<0.0001)$, initial conscious level $(p<0.03)$ and respiratory assistance $(p<0.002)$. Lesion level, multiple injuries, initial YSS, and vegetative disorders were not significantly correlated with survival time (see table 2).

\section{Discussion}

Two issues must be discussed briefly before the results are considered. First, because risk of death of an SCI patient is greatest in the first year following injury, only this period was analysed in the present study.

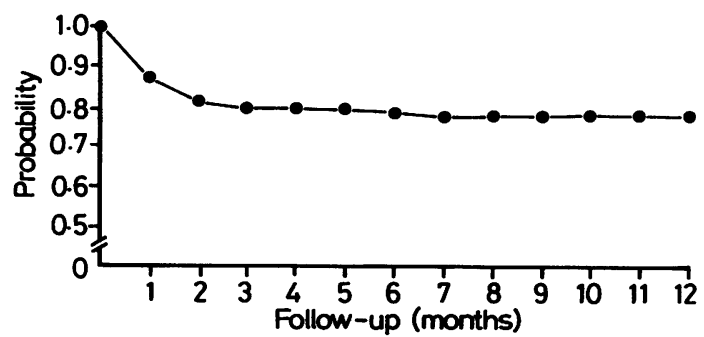

Fig 1 Survival curve for the total sample.

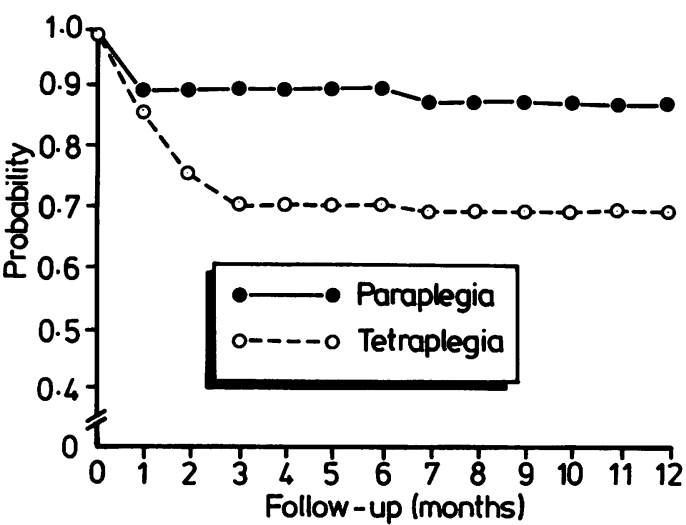

Fig 2 Survival curves for tetraplegic and paraplegic patients.

Second, the present study does not consider factors determining the patient's death (such as infections). Our objective was to determine whether a relation existed between survival and initial factors accessible to the clinician.

One of the problems of a prognostic study relates to the need for systematic inclusion of all SCI patients. ${ }^{7}$ If a selection bias is present, results will undeniably be altered. This bias would arise if secondary admissions in specialised wards were included because of the exclusion of all subjects who died during initial admission. A way to reduce this bias in our sample was to include only SCI patients admitted on the day of the injury. ${ }^{7}$ Only patients who died on the road or during the transfer to the hospital were not included in the present sample. The optimal solution, although impossible to achieve, would be to enrol and examine patients at the time of the accident.

Even though a peak was found in the age group 20 to 40 years, $42 \%$ of the sample was over 40 years; thus spinal cord injuries are not confined exclusively to young people. ${ }^{15}$ Forty seven per cent of the tetraplegic patients and $53 \%$ of the paraplegic patients have a complete lesion (YSS $=0$ ). The almost equal number of paraplegic patients and tetraplegic patients with complete lesions is a reflection of our sample being of

Table 2 Multivariate analysis of predictors of survival

\begin{tabular}{ll}
\hline Predictors & Significance (p value) \\
\hline Age & 0.0001 \\
Initial consciouness & 0.03 \\
Respiratory assistance & 0.002 \\
Multiple injuries & 0.92 \\
Lesional level & 0.84 \\
Initial YSS & 0.18 \\
Vegetative troubles & 0.43 \\
\hline
\end{tabular}


Table 3 Mortality rates for tetraplegic patients in survival series

\begin{tabular}{lc}
\hline Survival series & Mortality rates \\
\hline Silver (1968) & \\
Hardy $(1976)^{3}$ & $18 \%$ \\
Mesard (1978) & $13 \%$ \\
Sneddon (1982) & $26 \%$ \\
Ravichandran (1982) & $5 \%$ \\
Daverat (1988) & $2.4 \%$ \\
\hline
\end{tabular}

consecutive primary admissions. These results differ from previously published series because such series are based on both primary and secondary admissions to rehabilitation centres. Upon admission, $13 \%$ of the patients were in coma and $60 \%$ had normal consciousness. These results are in agreement with other major studies. ${ }^{11}$ is Among multiple injuries, thoracic injuries are most frequently observed; $25 \%$ in our series, $29 \%$ in Adli's, ${ }^{16}$ and $20 \%$ in Senegas's. ${ }^{6}$ However, rates for limb injuries (17\% in our series) vary considerably in the literature ${ }^{1516}$ depending on whether or not units admit multiple injuries and seriously head injured patients.

Our survival curve confirms the existence of three mortality stages in SCI patients put forward by Kraus. ${ }^{4}$ An initial period where mortality rates are extremely high ( 1 week in Kraus's study, 1 month in ours), a secondary period where death rates are lowered (6 months in Kraus's study, 3 months in ours) and finally a third period where life expectancy of SCI patients reaches the rates of an healthy population.

It is difficult to compare the present results with previously published studies. Our sample benefited from the considerable recent progress in medical care while the major studies on the topic were done several years ago (for example, Guttmann's series was observed during World War II). Also, series previously studied are often disparate, this being true for the subjects' as well as for the severity of the cord lesions. Finally, several studies have included secondary admissions, a factor which greatly diminishes mortality rates. ${ }^{17}$ Results of the most important studies that dealt with survival of tetraplegic patients ${ }^{2-518} 19$ are presented in table 3. Survival rates in tetraplegic patients are lower than those obtained in the present study. The higher death rate in our sample can be explained by the catchment of our emergency ward, where most patients with multiple injuries from surrounding areas are admitted. During the initial phase of their hospital stay, these patients have a high mortality and this greatly reduces the number of admissions in specialised units.

Three independent predictors of survival rates were found in our study: age, initial consciousness and respiratory assistance. The present results are not
Table 4 Mortality rates as a function of age, lesional level, and severity of the neurological lesion

\begin{tabular}{llll}
\hline & \multicolumn{2}{l}{ Mean age $(y r)$} \\
\cline { 2 - 4 } $\begin{array}{l}\text { Lesional } \\
\text { level }\end{array}$ & $\begin{array}{l}\text { Complete } \\
\text { lesion }\end{array}$ & $\begin{array}{l}\text { Incomplete } \\
\text { lesion }\end{array}$ & $\begin{array}{l}\text { Mortality } \\
\text { rate }\end{array}$ \\
\hline C1-C5 & 32 & 45 & $13 \%$ \\
C6-T1 & 41 & 42 & $43 \%$ \\
T2-T6 & 29 & 33 & $11 \%$ \\
>T7 & 33 & 39 & $12 \%$ \\
\hline
\end{tabular}

supported by previous series ${ }^{4518}$ which found the most important predictors to be age, lesion level and severity of the neurological injury. However these studies have used univariate analyses on their data set, and a confounding bias was likely to be present. In our study, lesion level was not found to be an independent predictor of survival because it is related to respiratory assistance which is in itself a more important predictor. Moreover, lesion level was analysed either as a continuous variable ( $p<0.07$ ), restricted to either paraplegia-tetraplegia $(\mathrm{p}<0.22)$ or to the site of lesion (C1-C5; C6-D1; D2-D6; > D7) $(\mathrm{p}<0.26)$. These results show that even if lesion level is analysed differently it still remains insignificant as a predictor of mortality. These results can also be explained by the existence of complex inter-relationships between lesion level, age and initial YSS as shown in table 4. Because tetraplegic patients are generally younger, a selection bias is created by the fact that mortality in tetraplegic patients is fairly low. Tetraplegic patients with $\mathrm{Cl}-\mathrm{C} 5$ lesions who are older and have a complete lesion usually die before reaching the hospital. The only tetraplegic patients who are admitted to the hospital either have an incomplete lesion or if completely lesioned are younger. These patients represent only $3 \%$ of our sample.

From the present results we can conclude that among the SCI patients who are admitted to the hospital on the day of the accident, $20 \%$ die during the first 3 months after the injury; $29 \%$ among tetraplegic patients and $11 \%$ among paraplegic patients. Statistical analyses enabled us to isolate three predictors of survival: age, initial consciousness and respiratory assistance. The present results demonstrate that if SCI patients are transferred shortly after their admission to a specialised unit, the lesional level and the severity of the neurological lesion are not predictors of survival. There, however, remain extrinsic factors common to all multiple injuries and not specifically related to a spinal cord lesion.

The authors thank J Senegas and P Erny for allowing our team to examine their patients. We also thank Dr F Dabis for useful comments on the manuscript. 


\section{References}

1 Guttmann L. Rehabilitation after injuries to the spinal cord and cauda equina. Br J Phys Med 1946;9:162-71.

2 Ravichandran G, Silver JR. Survival following traumatic tetraplegia. Paraplegia 1982;20:264-9.

3 Hardy AG. Survival periods in traumatic tetraplegia. Paraplegia 1976;14:41-6.

4 Kraus FJ. Survival with an acute spinal cord injury. $J$ Chron Dis 1979;32:269-83.

5 Mesard L, Carmody A, Mannarino E, Ruge D. Survival after spinal cord trauma: a life table analysis. Arch Neurol 1978;35:78-83.

6 Senegas J, Vital JM, Barat M, Caillé JM, Dabadie P. Traumatismes du rachis cervical. Encyclopédie MédicoChirurgicale, Appareil locomoteur 1987;15825A10:21.

7 Daverat P, Sibrac MC, Dartigues JF, Mazaux JM, Marit E, Debelleix X, Barat M. Early prognostic factors for walking in spinal cord injuries. Paraplegia 1988; 26:255-61.

8 Daverat $\mathrm{P}$, Sibrac MC, Barat M, et al. Valeur prédictive de l'examen initial dans la reprise de la marche chez les blessés médullaires à propos de 157 cas consécutifs. Annales de Réadaptation et Médecine Physique 1987; 30:369-79.

9 Chehrazi B, Wagner F, Collins W, Freeman D. A scale for evaluation of spinal cord injury. J Neurosurg 1981; 54:310-5.
10 Frankel HL, Hanckock DO, Hyslop G, et al. The value of postural reduction in the initial management of closed injuries of the spine with paraplegia and tetraplegia. Paraplegia 1969;14:262-75.

11 Maynard FM, Reynolds GG, Fountain S, Wilmot C, Hamilton R. Neurological prognosis after traumatic quadriplegia. J Neurosurg 1979;50:611-6.

12 Kaplan EL, Meier P. Non parametric estimation from incomplete observations. J Am Statist Assoc 1958; 53:457-81.

13 Cox DR. The Analysis of Binary Data. London: Chapman and Hall, 1970.

14 Cox DR. Regression models of life tables. J Statist Soc 1972;34:187-220.

15 Harris P, Karmi MZ, Marclemont E, D'Albret M, Paul KS. The prognosis of patients sustaining severe cervical spine injury (C2-C7 inclusive). Paraplegia 1980;18:324-30.

16 Adli G. Lésions associées et paraplégie. Annales de Médecine Physique 1978;21:468-77.

17 Minaire P, Demolin J, Bourret J, et al. Life expectancy following spinal cord injury: a ten years survey in the Rhône Alpes Region, France, 1969-1980. Paraplegia 1983;21:11-5.

18 Silver JR, Gibbon NO. Prognosis in tetraplegia. Br Med J $1968 ; 4: 79-83$.

19 Sneddon DG, Bedbrook G. Survival following traumatic tetraplegia. Paraplegia 1982;20:201-7. 